\title{
Post-Acute Traumatic Brain Injury Rehabilitation Treatment Variables: A Mixed Methods Study
}

\author{
Victoria Harding $^{1 *}$, Cynthia O'Donoghue ${ }^{2}$, Cara Meixner ${ }^{2}$, Frank Lewis ${ }^{3}$, Gordon Horn ${ }^{4}$, Robert Russell ${ }^{1}$ \\ ${ }^{1}$ NeuroRestorative Research Institute, Boston, MA; ${ }^{2}$ James Madison University, Harrisburg, VA; ${ }^{3}$ Medical College of Georgia at Augusta University; \\ NeuroRestorative Research Institute, Augusta, GA; ${ }^{4}$ Florida State University, College of Medicine, NeuroRestorative Research Institute, Orlando, FL, \\ United States
}

Purpose: This study explores gains in function, measured by the Mayo-Portland Adaptability Inventory-4 (MPAI-4) and qualitative interviews, of individuals who participated in a Post Hospital Interdisciplinary Brain Injury Rehabilitation - Residential (PHIDBIR-R) program as part of their recovery from brain injury.

Methods: The study uses a mixed methods design to identify correlates and explore pathways to functional recovery. Change scores from the MPAI-4 were derived to identify participants with greatest functional improvement. Qualitative interviews were employed to understand PHIDBIR-R program constructs associated with functional improvement. MPAI-4 data were derived from a bank of 135 PHIDBIR-R programs in 22 states. Participants were adults who sustained a brain injury and participated in a PHIDBIR-R program. 57 participants were identified as highest scorers; 10 completed semi-structured interviews.

Results: Data were analyzed using constant comparison procedures and rigorous credibility techniques. Thirteen themes within four categories (support, therapies, continuum of care, environment of care) emerged, reflecting participants' understanding of constructs contributing to positive outcomes.

Conclusions: The results provided a cogent framework for program development, stakeholder program selection, and advocate and legislator considerations.

Keywords: Brain injuries, Rehabilitation, Patient outcome assessment, Qualitative research

\section{INTRODUCTION}

Traumatic brain injury (TBI) is an alteration in brain function or other evidence of brain pathology caused by an external force. These injuries manifest as mild, moderate, or severe impairments to one or more areas, such as cognition, communication, memory, concentration, reasoning, physical functions, and psychosocial behavior [1].

The consequences of brain injuries are numerous with the potential to create lifelong challenges for survivors and their families. Stories involving TBI permeate the news: the high-school athlete concussed in a football game, the soldier wounded in an explosive blast, and the teenager injured in a car accident. In these scenarios, futures transition from navigating routine activities to struggling to function.

A formidable fact surrounding these circumstances is that brain injury does not discriminate - it can happen to any person, at any time. Each year in the United States, 1.7

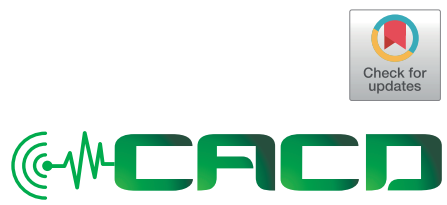

Received: September 26, 2017 Accepted: December 27, 2017

\section{Correspondence: \\ Victoria Harding}

NeuroRestorative Research Institute, 313 Congress Street, Boston, MA 02120, United States

Tel: +17814715272

Fax: +15403013560

E-mail:

victoria.harding@neurorestorative.com

(C) 2017 The Korean Association of SpeechLanguage Pathologists

This is an Open Access article distributed under the terms of the Creative Commons Attribution Non-Commercial license (http:// creativecommons.org/licenses/by-nc/4.0/) which permits unrestricted non-commercial use, distribution, and reproduction in any medium, provided the original work is properly cited. 
million TBIs occur either as an isolated injury or in conjunction with other injuries or illnesses. In the U.S., TBI is a contributing factor to nearly a third (30.5\%) of all injury-related deaths [2] and figures indicate that 5.3 million people live with a TBI-related disability [3]. Annually, TBIs cost Americans $\$ 76.5$ billion in medical care, rehabilitation, and loss of work $[4,5]$.

Other etiologies of brain injury further elevate these numbers. The annual incidence of stroke is 795,000 [6]. Further, the annual estimate of brain tumors is 64,530 , along with 27,000 aneurysms, and 20,000 viral encephalitis cases [6-8]. No national data are available for anoxic brain injury and other subtypes [1]. When all types of brain injury are aggregated, the annual occurrence in the U.S. approaches 8.5 million.

In addition, brain injuries reach beyond the individual who has sustained the TBI, affecting the lives of loved ones. Griefstricken families witness trauma, entering a reality in which survival is the daily hope. Improvements in medical care have improved life expectancy, yielding a steady increase in the number of older adults living with a brain injury $[9,10]$.

Once evident that an individual will survive the brain injury, goals focus on regaining lost function or rehabilitation. Just as each individual is unique, so is each recovery. Families commonly observe physical disabilities, impaired learning, and personality changes post injury. Nearly 20 years ago, the National Institutes of Health held a conference wherein an expert panel recommended that patients with TBI receive an individualized rehabilitation program based on the patient's unique strengths and capacities, and adapted to needs over time. The group further advised that persons with moderate to severe brain injuries have individually tailored treatment programs that draw on the coordinated skills of various specialists [11].

Past research of rehabilitation following brain injury has often focused on the evaluation of a specific treatment modality or of a program's efficacy as quantified by outcomes measurements. Many studies have sought to determine if rehabilitation has been successful, perhaps to the detriment of learning how rehabilitation has been efficacious. Studying how rehabilitation works over time is important in learning more about the individual and family experience while advancing an understanding of measured functional improvements.

Current research explores the therapies and interventions that facilitate long-term recovery of function. Individuals follow diverse recovery paths because there are a wide variety of options for rehabilitation [12]. This study focuses on PostHospital Inter-Disciplinary Brain Injury Rehabilitation - Residential (PHIDBIR-R) programs, which are 24-hour, 7-days a week rehabilitative care programs delivered in non-hospital, home-like, community-based environments. PHIDBIR-R programs strive to implement effective therapeutic interventions, supports, and services that maximize functional gains; these programs are judged on their ability to produce improvements in function [13].

While research efforts have focused on demonstrating positive outcomes, the identification of attributes that contribute to how improvement happens is largely untouched [13-18]. Although several PHIDBIR-R programs report positive outcomes $[19,20]$, the empirical evidence is limited and studies habitually focus on quantitative analysis. Including a qualitative component may provide insight into the PHIDBIR-R, eludicating how these experiences advance an understanding of functional improvements.

\section{METHODS}

This study applied a mixed methods approach with two phases (Table 1). Phase 1, a participant selection variant [21], employed a quantitive approach to identify participants for Phase 2, which entailed qualitative inquiry. Participants were selected from a convenience sample from a large neurehabili-

Table 1. Mixed Methods Approach: Study Phases 1 and 2

\begin{tabular}{|c|c|c|c|c|}
\hline Phase & Strategy & Sample & Goal & Analysis \\
\hline 1 & $\begin{array}{l}\text { Quantitative MPAI-4 data analysis: } \\
\text { admission scores compared to } \\
\text { discharge scores }\end{array}$ & $\begin{array}{l}\text { All program completers from all } \\
\text { sites during one year period of } \\
\text { study }(\mathrm{N}=712)\end{array}$ & $\begin{array}{l}\text { Identify at least } 50 \text { participants with } \\
\text { greatest overall reduction in } \\
\text { T-scores (indicates reduction in } \\
\text { disability) }\end{array}$ & $\begin{array}{l}\text { Serial assessment using repeated } \\
\text { measures design }\end{array}$ \\
\hline 2 & $\begin{array}{l}\text { Qualitative data collection: semi- } \\
\text { structured interviews }\end{array}$ & $\begin{array}{l}\text { 10-50 participants with greatest } \\
\text { functional gains and their family } \\
\text { members }\end{array}$ & $\begin{array}{l}\text { Identify emerging themes of the } \\
\text { rehab program associated with } \\
\text { functional improvement }\end{array}$ & $\begin{array}{l}\text { Identification of common and } \\
\text { individual themes/constructs }\end{array}$ \\
\hline
\end{tabular}


tation company with more than 25 PHIDBIR-R programs nationally. Human subjects approval was secured through an accredited university's Institutional Review Board (Protocol \# 14-0298).

A repeated measures design was used in Phase 1 to compare scores of the Mayo-Portland Adaptability Inventory-4 (MPAI-4) [22] at admission and at discharge $(n=712)$. Calculating difference in T-scores, all eligible participants were rank ordered and assigned to one of four categories of highest to lowest achievement. Additional analyses were completed to ascertain 1) which parts of the MPAI-4 showed statistically significant change (paired t-tests); and 2) which of the 29 items contributed most to change scores (MANOVA).

Phase 1 identified 57 potential subjects with the highest change scores, rank ordered from greatest to least change per MPAI-4. Beginning with the top performers, these individuals were invited to participate in Phase 2. Ten persons consented and interviews proceeded until saturation of themes was confirmed. Interviews were transcribed, coded, and analyzed.

\section{RESULTS}

\section{Phase 1}

The total MPAI-4 change scores were arranged into four groups: highest (Group 1a); high-mid (Group 1b); mid-low (Group 1c) and the lowest (Group 1d) as shown in Table 2. Table 3 displays participant characteristics.

Beyond data on total T-score change, additional analyses were warranted. The 29 items on the MPAI- 4 were converted to T-scores within three subscales: Ability Index, Adjustment Index, and Participation Index. A question to inform Phase 2 of the study emerged: "Which of the three subscales accounts for the most change in Group la?" Accordingly, paired T-tests were conducted; improvement on each of the MPAI-4 subscale T-scores (Table 4) was statistically significant, with par-

Table 2. Participant Groupings by MPAI-4 Change Scores

\begin{tabular}{lcccc}
\hline $\begin{array}{l}\text { Group } \\
\text { Sample }\end{array}$ & N & $\begin{array}{c}\text { Change } \\
\text { score range }\end{array}$ & $\begin{array}{c}\text { Mean change in } \\
\text { participation } \\
\text { T-score }\end{array}$ & SD \\
\hline Highest (1a) & 57 & $19-34$ & 22.31 & 3.99 \\
High-Mid (1b) & 40 & $16-18$ & 16.65 & .735 \\
Mid-Low (1c) & 55 & $13-15$ & 14.11 & .831 \\
Lowest (1d) & 47 & $2-12$ & 12 & 0 \\
\hline
\end{tabular}

The size of each of the four groups is not precisely $25 \%$ since individuals' scores fall into different ranges. ticipation accounting for the most change. This subscale includes: Initiation; Social contact; Leisure and recreational activities; Self-care; Independent living and homemaking; Transportation; Employment; and Managing money and finances.

Further analyses were conducted using a stepwise regression. The six significant MPAI-4 predictor variables [23] of inclusive of self-care, initiation, residence, motor speech, mobility, and impaired awareness were used. Results demonstrated three significant predictors: self-care, initiation, and residence, $\mathrm{R}^{2}=.87, F(3,53)=113.14, p<0.0001$ (adjusted $\mathrm{R}^{2}=.86$ ). Self-care predicted the largest portion of variance in discharge participation T-score (adjusted $\mathrm{R}^{2}=.72$ ).

\section{Phase 2}

Ten of 57 individuals consented to participate in phase 2. Data were collected via face-to-face, semi-structured interviews. Eighteen process notes were written by the researcher, helping to standardize participant contact, review of informed consent, interview process, and recording. Member checking was completed with two participants, eliciting a $96 \%$ agree-

Table 3. Participant Characteristics

\begin{tabular}{lcccc}
\hline Characteristic & $\begin{array}{c}\text { Group 1a } \\
\text { Highest } \\
25 \%\end{array}$ & $\begin{array}{c}\text { Group 1b } \\
\text { High-Mid } \\
25 \%\end{array}$ & $\begin{array}{c}\text { Group 1c } \\
\text { Mid-Low } \\
25 \%\end{array}$ & $\begin{array}{c}\text { Group 1d } \\
\text { Lowest } \\
25 \%\end{array}$ \\
\hline Sample Size & 57 & 40 & 55 & 47 \\
Age (y) & 46 & 45 & 42 & 42 \\
Male/Female \% & $67 / 33$ & $73 / 27$ & $86 / 14$ & $83 / 17$ \\
TBls \% & 68 & 63 & 66 & 53 \\
CVAs \% & 14 & 23 & 11 & 21 \\
Anoxia/Hypoxia \% & 2 & 5 & 11 & 6.4 \\
Length of Stay & 5.1 & 4.7 & 3.8 & 4.8 \\
$\quad$ (months) & & & & \\
$\begin{array}{l}\text { Onset of Injury to } \\
\text { Admission (months) }\end{array}$ & 6.5 & 14.0 & 4.6 & 18.0 \\
\hline
\end{tabular}

Table 4. Subscale Change

\begin{tabular}{lccccc}
\hline MPAI-4 Index & $\begin{array}{c}\text { Mean } \\
\text { Adm-D/C } \\
\text { Difference }\end{array}$ & $\begin{array}{c}\text { Standard } \\
\text { Error } \\
\text { Mean }\end{array}$ & t & df & $\begin{array}{c}\text { Sig. } \\
\text { 2-tailed }\end{array}$ \\
\hline Ability & 15.54 & 1.55 & 9.97 & 56 & .001 \\
Adjustment & 11.60 & 1.33 & 9.02 & 56 & .001 \\
Participation & 22.31 & .52 & 42.35 & 56 & .001 \\
\hline
\end{tabular}

Adm- $D / C$ refers to the mean score change from admission to discharge on the MPAI. 
Table 5. Categories, Themes, and Idea Clusters

\begin{tabular}{|c|c|c|c|}
\hline Category $(1,2,3,4)$ Theme $(a, b, c, d)$ & Idea Cluster 1 & Idea Cluster 2 & Idea Cluster 3 \\
\hline \multicolumn{4}{|l|}{ (1) Support } \\
\hline (a) Paid Staff & Supportive Stance & Attitude & Skill \\
\hline (b) Program Peers & Collectiveness Feeling & Competition & $x$ \\
\hline (c) Family Support & Frequency of Visits & Involvement in Treatment & $x$ \\
\hline (d) Higher Power & Saved from Death & Source of Strength & Control of Outcomes \\
\hline \multicolumn{4}{|l|}{ (2) Therapies } \\
\hline (a) Staff Skills & Specialties & Availability; Individual Treatment & $x$ \\
\hline (b) Self-Assessment & Describe Adaptation & Attitude of Self-Efficacy & $x$ \\
\hline (c) Equipment or Techniques & Level of Supervision & $x$ & $X$ \\
\hline \multicolumn{4}{|l|}{ (3) Continuum of Care } \\
\hline (a) Time of Treatment & After Hospital Experience & Community Integration & $x$ \\
\hline (b) Accessing & Real World & $x$ & $x$ \\
\hline (c) Levels of Care & Progress in One Setting & $x$ & $x$ \\
\hline \multicolumn{4}{|l|}{ (4) Environment of Care } \\
\hline (a) Daily Schedule & Structured Day & Work Ordered Day & $x$ \\
\hline (b) Physical Set Up & Home-Like & Barrier-Free & $x$ \\
\hline (c) Location and Setting & Community Imbedded & Transportation & Proximity to Home \\
\hline
\end{tabular}

ment that was determined via NVIVO-10 analysis of code coverage. One hundred percent agreement on category and theme descriptions was obtained via member checking. Two peers, both psychologists, participated in calibrated peer review. Each reviewed two different coded transcripts; agreements for these reviews were $98 \%$ and $96 \%$, respectively. Once analyzed, data were organized into four categories, each describing a major finding (Table 5).

\section{DISCUSSION}

Quantitative findings showed statistically significant improvement in all three MPAI-4 subtest categories, with Participation having the greatest explanatory power. Regression analysis revealed three significant predictors: self-care, initiation, and residence. The self-care finding mirrors the primary focus of rehabilitation programs. Initiation findings suggest that success may be tied to ability to self-initiate activity [23]. Residence (e.g., independent living responsibilities) also maps to areas cultivated in the rehabilitation process.

Qualitative findings illuminated 13 themes within four categories, which represent facets that participants associate with successful outcomes. The themes that contributed to improvement are: paid staff; peers in the program; families of the participants; a higher power; the skills of the paid staff; the ability to assess oneself; particular equipment or techniques; the timing of accessing the PHIDBIR-R program; accessing level of care as part of a continuum; providing different levels of care; following a daily schedule; the physical plant or set up of the program; and location of the program. The results suggest a framework for PHIDBIR-R programming of compulsory construct inclusion, training, supports, and services.

This study confirms that qualitative interviews contribute to a more comprehensive, nuanced insight into survivors' functional improvement. This research offers important considerations for optimizing functional improvement following brain injury. Illuminated are evidenced-based themes for not only PHIDBIR-R providers, but to stakeholders wishing to improve or establish high quality programs. Undoubtedly, PHIDBIR-R providers should consider these constructs, as themes were identified by the highest achievers as contributors to success. Individuals served, their families and funders, should receive education about these programmatic essentials just as advocates, public policy makers, and the rehabilitation industry might apply these findings to promote optimal outcomes.

\section{Study limitations}

Study limitations may include generalizability of results across differing rehabilitation providers or settings. 


\section{CONCLUSIONS}

The purpose of this study was to reach beyond the traditions of demonstrating an intervention as effective in reducing impairment or disability during neurological rehabilitation recovery. Specifically, identifying the factors that most influence how improvement happens was the focus. The findings of self-care and initiation as the top two predictors of positive outcomes replicated the findings of earlier research [23] and suggest that application of skills is necessary. In addition, the results also support interdisciplinary approaches to complex rehabilitation conditions. However, the qualitative analyses revealed four themes to recovery from the person-centered perspective including support; therapeutic interventions; continuum of care approach; and the physical setting where treatment was provided. The combination of quantitative and qualitative approaches likely provides the best assessment of program and person-centered outcomes. This investigation provides a cogent framework for program development, stakeholder program selection, and advocate and legislator considerations.

\section{REFERENCES}

1. Brain Injury Association of America. About brain injury. http:// www.biausa.org/about-brain-injury.htm. Published 2012. Accessed September 1, 2016.

2. Faul M, Xu L, Wald MM, Coronado VG. Traumatic Brain Injury in the United States: Emergency Department Visits, Hospitalizations and Deaths 2002-2006. Atlanta: Centers for Disease Control and Prevention, National Center for Injury Prevention and Control; 2010.

3. Thurman D, Alverson C, Dunn K, Guerrero J, Sniezek J. Traumatic brain injury in the United States: a public health perspective. J Head Trauma Rehabil. 1999;14(6):602-615.

4. Finkelstein EA, Corso PS, Miller TR. The Incidence and Economic Burden of Injuries in the United States. New York: Oxford University Press; 2006.

5. Coronado VG, McGuire LC, Faul MF, Sugerman DE, Pearson WS. The epidemiology and prevention of TBI. In: Zasler ND, Katz DI, Zafonte RD, eds. Brain injury medicine: principles and practice. 2nd ed. New York, NY: Demos Medical Publishing; 2012:84-100.

6. Centers for Disease Control and Prevention. Prevalence and most common causes of disability among adults: United States 2005. MMRW. 2009;58(6):421-426.

7. Central Brain Injury Tumor Registry of the United States. CBTRUS Statistical Report: Primary Brain and Central Nervous System Tumors Diagnosed in the United States in 2004-2008. Hinsdale, Il:
Central Brain Tumor Registry of the United States; 2012.

8. National Heart Blood and Lung Institute. What is an aneurysm? Bethesda, Md: National Institutes of Health; 2011.

9. Cifu DX. Rehabilitation of the elderly crash victim. Clin Med Geriatr. 1993;9:473-483.

10. Cifu DX, Means KM, Cunie DM, Gershkoff AM. Geriatric rehabilitation: Diagnosis and management of acquired disabling disorders. Arch Phys Med Rehabil. 1993;74:406-412.

11. National Institutes of Health. Rehabilitation of persons with traumatic brain injury. http://consensus.nih.gov/1998/1998traumati cbraininjury109html.htm Published October 10, 1998. Accessed September 1, 2016.

12. National Institute for Neurological Disorders and Stroke. http:// www.ninds.nih.gov/ Published 2013. Accessed September 1, 2016.

13. Willer B, Button J, Rempel R. Residential and home-based rehabilitation of individuals with traumatic brain injury: a case control study. Arch Phys Med Rehabil. 1998;80(4):399-406.

14. Salazar AM, Warden DL, Schwab K, Spector J, Braverman S, Walter J, et al. Cognitive rehabilitation for traumatic brain injury: a randomized trial. Defense and Veterans Head Injury Program (DVHIP) Study Group. JAMA. 2000;283 (23):3075-3081.

15. Vanderploeg RD, Schwab K, Walker WC, Fraser JA, Sigford BJ, Date ES, et al. Rehabilitation of traumatic brain injury in active duty military personnel and veterans: defense and veterans brain injury center randomized controlled trial of two rehabilitation approaches. Arch Phys Med Rehabil. 2008;89(12):2227-2238.

16. Ponsford J, Harrington H, Olver J, Roper M. Evaluation of a community-based model of rehabilitation following traumatic brain injury. Neuropsychological Rehabilitation. 2006;16(3):315-328.

17. Prigatano GP, Klonoff PS, O'Brien KP, Altman I, Amin K, Chiapello DA, Shepherd J, Cunningham M, Mora M. (1994). Productivity after neuropsychologically oriented, milieu rehabilitation. Journal of Head Trauma Rehabilitation 9(1): 91-102.

18. Cicerone KD, Mott T, Azulay J, Friel, JC. Community integration and satisfaction with functioning after intensive cognitive rehabilitation for traumatic brain injury. Arch Phys Med Rehabil. 2004;85 (6):943-950.

19. NeuroRestorative. Focused on outcomes. http://www.neurorestorative. com/our approach/outcomes Published 2013. Accessed September 1, 2016.

20. ReMed. Resources. http://www.remed.com/index.php?option= com_content\&task=view\&id=31\&Itemid=36. Published 2014. Accessed September 1, 2016.

21. Creswell JW, Plano Clark VL. Designing and conducting mixed methods research. Thousand Oaks, Ca: Sage; 2011.

22. Malec J. The Mayo Portland Adaptability Inventory. http://www. tbims.org/combi/mpai/ Published 2005. Accessed September 1, 2016.

23. Lewis F, Horn G. Traumatic brain injury: Analysis of functional deficits and posthospital rehabilitation outcomes. J Spec Oper Med. 2013;13(3):56-61. 